\title{
Effect of Covid-19 pandemic induced lockdown on sleep wake pattern and personal well-being of undergraduate medical students of West Bengal
}

\author{
Sujata Biswas', Bhaskar Saha², Indranil Halder ${ }^{3}$, Gandhari Basu ${ }^{4}$, Anupam Ghosh $^{5}$ \\ ${ }^{1}$ Associate Professor, ${ }^{2}$ Assistant Professor, Department of Physiology, College of Medicine and JNM Hospital, West \\ Bengal University of Health Science, ${ }^{3}$ Associate Professor, Department of Chest Medicine, College of Medicine and \\ JNM Hospital, West Bengal University of Health Science, ${ }^{4}$ Associate Professor, Department of Community Medicine, \\ College of Medicine and JNM Hospital, West Bengal University of Health Science, ${ }^{5}$ Consultant, Tata Consultancy \\ Services Limited
}

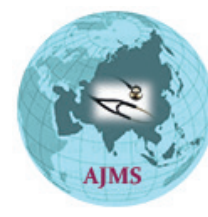

\section{A B S T R A C T}

Background: COVID-19 pandemic induced lockdown and the social restrictions had a profound impact on the circadian rhythm driven sleep-wake schedule of the home confined population. Aims and Objective: Our study explored the effect of COVID-19 pandemic induced lockdown on sleep wake pattern and personal well-being of medical students of West Bengal. Materials and Methods: An observational, questionnaire-based online survey was conducted using the URL linked Google form. The online survey was conducted through social media platforms as per CHERRIES checklist guideline. Information on demographic profile, before and after lockdown sleep-wake pattern, social wellbeing and general lifestyle was obtained. Any student with any sleeping disorder or on drugs was excluded. Mean (SE), median, range, proportion was calculated as per attributes. Fisher's exact chi square test and paired t test was done to test association and to compare means of the attributes. Results: The mean age of students was 20.26 years. The average daily time spent on electronic media got doubled during lockdown. Sleep disorder was reported by $53.0 \%$ male and $47.0 \%$ students. More than half of respondents reported increased napping during daytime, irregular timing for meal intake and low mood. Anxiety was present in every two out of three participants. Females gained more weight during lockdown. The gender difference in sleep duration became significant. Lockdown effect on the average daily media time was significant. The sleep disturbance at night and physical inactivity was significantly more among female students. Access this article online Website: http://nepjol.info/index.php/AJMS DOI: 10.3126/ajms.v12i10.38354 E-ISSN: 2091-0576 P-ISSN: 2467-9100

Copyright (c) 2021 Asian Journal of Medical Sciences

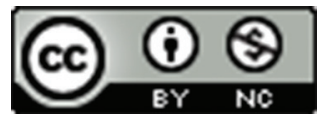

This work is licensed under a Creative Commons Attribution-NonCommercial 4.0 International License. Conclusion: COVID-19 lockdown leads to delayed sleep-wake cycle, irregular meal timings and excessive digital exposure among medical students with gender based differential impact.

Key words: COVID-19; Lockdown; Circadian rhythm; Well-being; Digital media; Google form; CHERRIES guidelines

\section{INTRODUCTION}

The Corona virus induced pandemic has had its origin in Wuhan, China amidst outbreak of viral pneumonia in December 2019. The causative agent was named as severe acute respiratory syndrome coronavirus 2 (SARS-CoV-2). An epidemic that was initially regional very soon transformed to a worldwide pandemic. ${ }^{1,2}$
In India, from $3^{\text {rd }}$ of January, 2020 to $2^{\text {nd }}$ of June, 2021, 28,307,832 confirmed cases of COVID-19 with 335,102 deaths have been reported to World Health Organization. ${ }^{3}$ A total of 22,10,43,693 vaccine doses have been administered to the beneficiaries till $2^{\text {nd }}$ of June, 2021 in India. ${ }^{4}$ The first confirmed positive case of India was a 20-year-old female from Kerala whose swab became positive on 30 January $2020 .{ }^{5}$ Thereafter, the cases were 
consistently increasing in several states of India. The seriousness of the foreseen epidemic has forced our Government to announce an initial 21-day nationwide lockdown to interrupt the chain of transmission and as an effect the classes of all the medical institutions were suspended along with industries and others. First lockdown was followed in succession by three more lowdown phases. Phase wise unlocking was announced for improvement of the Indian economy. ${ }^{6}$ The nationwide lockdown in 2020 had generated online classes with partial social isolation from friends among medical under graduate students, too. This state of affairs allowed the students to choose favored time scale of sleep and wake that indirectly reveal their real circadian cull for sleep-wake schedule, subjective alertness and also food intake. The internal circadian rhythm adjusts these types of behaviors like sleep-wake cycle, physical activity, mood and alertness level. These can fluctuate over the whole day from highest level to nadir. The other external environmental factors such as sunlight (strongest one), long working hours, timing of meal intake, artificial light exposure via digital media also interact with the circadian cycle of human. ${ }^{7-9}$ Earlier researches from India revealed that, absolute lockdown leads to social jetlag, delayed sleep-wake pattern and excessive digital media exposure. ${ }^{10}$ The medical students like all other students were also forced to stay at home for entire period of lockdown that has lead more exposure to artificial digital media like mobile, laptop, TV, etc. It is a well-known fact that, more increase in screen time there is more change in sleep-wake schedule, shorten sleep duration and also more reporting of daytime tiredness. The behavioural and attention problems are also can't be ignored altogether. ${ }^{11,12}$ Studies indicated that, during the online classes, the students got obstacles in learning via $\mathrm{E}$ platforms. The problems faced were lack of motivation, sense of isolation due to physical absence of peers. It was evident that the home environment for learning purpose is not as favourable as in an educational institute..$^{13}$ In this situation, students are spending more time on digital screen and this would hamper their innate circadian rhythm.

\section{Aims and Objective}

The present survey was conducted to assess the sleep wake pattern, personal well-being before and during the lockdown and also to explore the effect of lockdown on the sleep wake pattern and personal well-being among the undergraduate medical students.

\section{MATERIALS AND METHODS}

An observational, online based, cross sectional questionnaire-based survey was conducted in last year among the undergraduate medical students of West Bengal,
India. The URL linked Google survey form was created by one researcher and then circulated through social media platforms like WhatsApp, Facebook, email account of the students, fellow faculties and different social medical groups. Ethical clearance was taken from the institutional ethical committee prior to the study. There was an informed consent statement as a part of the survey questionnaire at the beginning of the survey form. Design of the survey form was followed as per CHERRIES checklist guideline. ${ }^{14}$ The questionnaire consisted of a total of 33 self-administered questions in English using Google Forms (Google LLC, CA, and U.S.A.). The questions were on demographic profile, before and after lockdown sleep-wake pattern, social wellbeing and general lifestyle associated with medical student. The minimum time required to fill and submit may be about 7-10 minutes. Some questions from validated Munich Chronotype Questionnaire (MCTQ) and Morningness-Eveningness Questionnaire were used in this study to assess the work and free day sleep schedule. The Munich Chronotype Questionnaire was developed by Roenneberg et al. It has been used since year with 2000 onwards. The questionnaire consists of a core module that is needed to determine the chronotype and several additional, optimal modules on personal data, light exposure and substance use etc. This questionnaire estimates the chronotype based on the midpoint between sleep onset and offset on the work free days, corrected for over-sleep. Morningness-Eveningness Questionnaire is a 19-item questionnaire to assess the morningness and eveningness. Questions are framed in a preferential manner. ${ }^{15,16}$ Students were asked if they were anxious and feel insecure in medical profession as COVID-19 pandemic put a tremendous amount of pressure in medical fraternity. The history of past or current infection with the COVID-19 virus was also enquired in the form. Undergraduate medical students possessing a smart phone with internet connection was a pre requisite for inclusion in the study. All the students were informed regarding the objectives and rationale of the study. Duplicate responses were avoided by restricting multiple responses from a single email-address. The study was a single masked study with maintenance of strict confidentiality. The questionnaire had questions on socio-demographic variables, personal information, sleep wake cycle, physical activity, screen time, meal timing, personal well-being and mood. We excluded subjects with any sleeping disorder or on drugs which are known to effect sleep- wake pattern. The online survey was kept open for a period of seven days during third phase of the lockdown. A total 267 students responded from various medical colleges of west Bengal during this period.

\section{Ethics}

The present study was presented before the scientific review committee and it was modified as per their 
suggestion. Thereafter, it was conducted after obtaining permission from Institutional ethics committee.

\section{Statistical analysis}

The data were coded and put into MS Excel 2010. All the records were double checked and analysed with help of SPSS 22.0 (licensed) and Stat Calc version 8.2 software. Mean (SE), median, range was calculated for the quantitative attributes. Proportion was measured for qualitative attributes. Presence of association was done by either Fisher's exact chi square test wherever applicable or Yates corrected chi square. Paired t test was done to compare means of the attributes before and during lockdown.

\section{RESULTS}

The present study had a total of 267 respondents with mean (SE) age of $20.26( \pm 0.079)$ years. Majority $(97.4 \%)$ of students aged between 18 to 23 years. The students slept on an average of $6.26( \pm 0.079)$ and $6.37( \pm 0.107)$ hrs per day before and during lockdown respectively. The average daily time spent on electronic media got doubled during lockdown in comparison with pre lockdown period. The median screen time spent before and during lockdown were 3 and 6 hrs respectively. The average (SE) difference in daily screen time spent was 3.55 (0.130) hrs (Table 1). First professional MBBS students participated more (64.4\%) in this survey followed by second professional MBBS students. Two students declared themselves to be infected with COVID 19. At the time of survey, 261 students lived in a locality where strict lockdown was imposed. Among 267 students, $24.7 \%$ complained of sleep disorder, but only four (4) took medicine for this reason.

Our survey revealed that, napping during daytime, irregular timing for meal intake, eating and weight were increased in more than half of respondents during lockdown. Anxiety was reported by every two out of three participants. Walking was reported as mostly practiced physical activity followed by free hand and Yoga. Ninety-six students reported of doing no physical activity. In the period of lockdown, mood was low in more than half $(52.4 \%)$ students, but the relationship with other family members was improved among more than one-third (38.6\%) respondents. The choice of current profession was considered as wrong one by thirty-five $(35,13.1 \%)$ medical students. Twenty-one $(7.9 \%)$ students also expressed their desire to switch their profession, given scope. Nearly half $(49.8 \%)$ respondents thought time was flying during lockdown and 14.6\% thought of time dragging (Table 2).

The recent research revealed that, before lockdown, $77.9 \%$ students slept for five to seven hours a day, whereas $12.7 \%$ slept between eight to ten hrs daily. Females in the present study have more delayed onset for both sleep at night and wake up in morning during lockdown but not significant one. It was observed that, before lockdown, two-thirds $(67.8 \%)$ of the students spent one to three hrs while onethirds $(28.8 \%)$ of them spent three to six hrs per day on electronic media. This screen time duration was increased during lockdown. Nearly half $(48.7 \%)$ of participants spent three to six hours a day. The on-screen time was for duration between seven to fourteen hours in $43.4 \%$ students. There was some gender wise difference in the proportion of sleep duration and daily screen time spent, before and during lockdown, but the difference was not significant, but the difference in means of sleep duration before lockdown among male and female students became significant $(P=0.027)$ (Table 3$)$.

In the current study, there is marked increase in the number of students having delayed onset of sleep (82 vs. 23) during lockdown when compared with before lockdown. It was observed that, before lockdown, one hundred and twelve students (112) went to bed between 10 p.m. to 12 midnight, whereas the number was reduced to fifty-seven only during lockdown. In context with the wake-up time, the number of students who woke up between 6 a.m. to 8 a.m. was one hundred and sixty-seven (167), whereas the number reduced to ninety-two (92) during lockdown. It was also observed that, one hundred and thirty-five (135) students have delayed wake up time between 8 to 10 a.m. during lockdown. Eighteen students also reported to wake up between 10 a.m. to 12 noon (Figure 1 and 2).

It has been observed that, there was difference in the proportion of daily sleeping time before and during lockdown. In the present study, $62.7 \%$ students slept between one to four hrs per day during lockdown. The

\section{Table 1: Descriptive statistics of study respondents $(\mathrm{N}=267)$}

\begin{tabular}{|c|c|c|c|c|}
\hline Attributes & Mean & Median & Range & SE (mean) \\
\hline Age (years) & 20.26 & 20 & 7 & 0.079 \\
\hline Sleep duration before lockdown (hr) & 6.26 & 6 & 8 & 0.079 \\
\hline Sleep duration during lockdown (hr) & 6.37 & 7 & 10 & 0.107 \\
\hline Daily screen time any media before lockdown $(\mathrm{hr})$ & 3.07 & 3 & 8 & 0.091 \\
\hline Daily screen time any media during lockdown (hr) & 6.62 & 6 & 12 & 0.163 \\
\hline Daily screen time difference before and during lockdown(hr) & 3.55 & 3 & 12 & 0.130 \\
\hline
\end{tabular}


proportion was $37.3 \%$ before lockdown imposed. The similar scenario was also noted, if the sleep duration was more than eight hrs a day. There were two-fold increases in the proportion of daily sleep among respondents before and during lockdown (32.4\% vs. 67.6\%). Before lockdown, 181 students spent one to three hrs per day on electronic media, whereas, during lockdown, 130 and 116 students spent between four to six hrs and more than six hrs a day respectively. The average daily time spent on electronic media was increased more than double during lockdown and this difference was strongly significant $(P=0.000)$ (Figure 3 and Table 4).

\begin{tabular}{|c|c|}
\hline Variables & During lockdown (n, \%) \\
\hline \multicolumn{2}{|l|}{ Daytime napping } \\
\hline Increased & $145(54.3)$ \\
\hline Decreased & $25(9.4)$ \\
\hline No change/never napped & $97(36.3)$ \\
\hline \multicolumn{2}{|l|}{ Disturbance in night sleep } \\
\hline Mostly/often & $89(33.3)$ \\
\hline Occasionally & $75(28.1)$ \\
\hline Never & $103(38.6)$ \\
\hline \multicolumn{2}{|l|}{ Physical activity } \\
\hline Increased & $52(19.5)$ \\
\hline Decreased & $187(70.0)$ \\
\hline No change & $28(10.5)$ \\
\hline \multicolumn{2}{|l|}{ Appetite } \\
\hline Increased & $85(31.8)$ \\
\hline Decreased & $63(23.6)$ \\
\hline No change & $117(43.8)$ \\
\hline \multicolumn{2}{|l|}{ Meal time } \\
\hline Irregular & $154(57.7)$ \\
\hline No change & $123(42.3)$ \\
\hline \multicolumn{2}{|l|}{ Mood status } \\
\hline Elevated & $44(16.5)$ \\
\hline Low & $140(52.4)$ \\
\hline No change & $83(31.1)$ \\
\hline \multicolumn{2}{|l|}{ Anxiety over future life } \\
\hline Present & $177(66.3)$ \\
\hline Absent & $90(33.7)$ \\
\hline \multicolumn{2}{|l|}{ Relation with family members } \\
\hline Improved & $103(38.6)$ \\
\hline Worsened & $38(14.2)$ \\
\hline No change & $126(47.2)$ \\
\hline
\end{tabular}

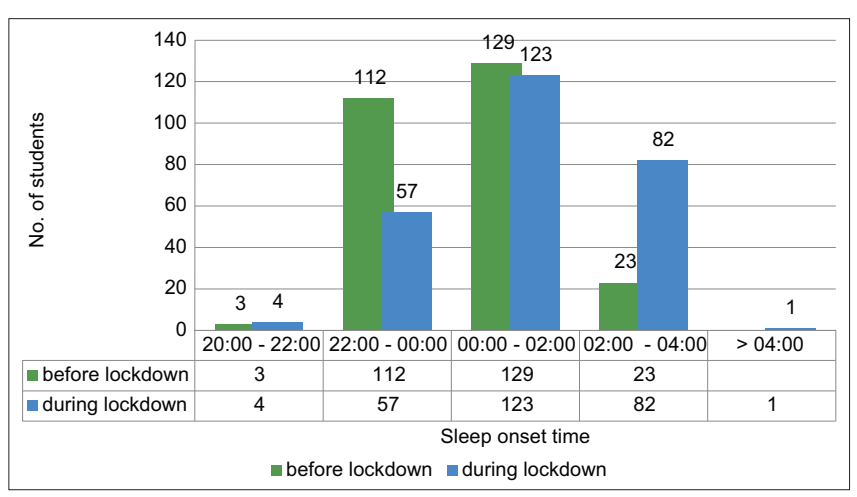

Figure 1: Sleep onset time before lockdown vs. during lockdown
The present study revealed that, $53.0 \%$ of male and $47.0 \%$ of female students had sleep disorder. Out of four respondents taking sleep related medication, three were males. Daytime napping was increased in both sexes. The difference in proportion of disturbance of sleep at night was significantly more among female students. Similar significant difference was observed in reduced physical activity among females in respect with male students. $(P<0.05)$ The difference in proportion of daytime napping, mood status and eating were not significant, but the appetite was more in female. The irregularity in meal intake was also more observed among female students, though the difference was not significant. The weight gain was also more among female students $(57.4 \%$ vs. $42.6 \%$ ) (Table 5).

\section{DISCUSSION}

The present research was conducted to assess the effect of COVID-19 imposed lockdown on the sleep-wake cycle, timing of meal intake, daily screen time spent on digital media and personal well-being of the medical students of West Bengal. Our study also tried to explore the effect of gender on the similar attributes. Sleep related problems are of major concern among students and it has long term impact on general well-being. The key findings indicate that, this pandemic forced stay at home has brought change in all the attributes considered under present study. The present study findings on both late sleep onset and late wake-up time are similar with earlier surveys. The study compared the sleep wake pattern in weekends versus week days. The sleep onset and wake-up time of the students was delayed for all ages and both gender in the present survey. In a national survey, irrespective of age group and sex, both of these times were delayed significantly as compared to pre lockdown. The time preferred to sleep at night and wake up in morning for majority of students extended during lockdown as earlier study. ${ }^{10,17}$ In our study, one-third

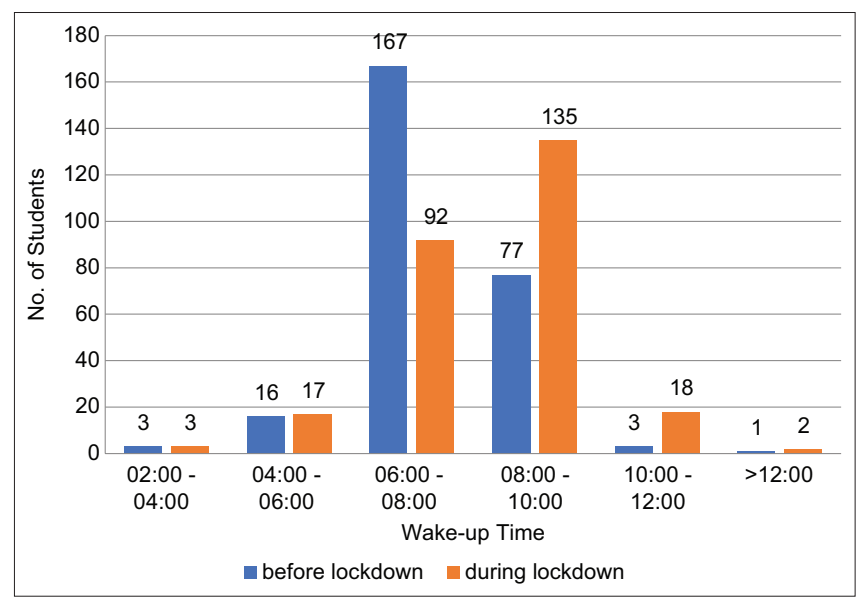

Figure 2: Wake up time before lockdown vs. during lockdown 


\begin{tabular}{|c|c|c|c|c|c|}
\hline \multirow[t]{2}{*}{ Variables } & \multicolumn{2}{|c|}{ Gender } & \multicolumn{2}{|c|}{ Mean (SE) } & \multirow[t]{2}{*}{ Statistics } \\
\hline & $\begin{array}{c}\text { Male } \\
\text { Frequency (\%) }\end{array}$ & $\begin{array}{c}\text { Female } \\
\text { Frequency (\%) }\end{array}$ & Male & Female & \\
\hline \multicolumn{6}{|c|}{ Sleep duration before lockdown (hrs) } \\
\hline $2-4(n=25)$ & $17(68.0)$ & $8(32.0)$ & $6.44(0.108)$ & $6.09(0.114)$ & $X^{2}=3.176, P=0.204$ \\
\hline $5-7(n=208)$ & $104(50.0)$ & $104(50.0)$ & & & $F=0.369$ \\
\hline $8-10(n=34)$ & $16(47.1)$ & $18(52.9)$ & & & $\begin{array}{r}\mathrm{t}=2.227 \\
P=0.027\end{array}$ \\
\hline \multicolumn{6}{|c|}{ Sleep duration during lockdown(hrs) } \\
\hline $2-4(n=42)$ & $26(61.9)$ & $16(38.1)$ & $6.46(0.141)$ & $6.27(0.161)$ & $X^{2}=5.17, P=0.075$ \\
\hline $5-7(n=154)$ & $70(45.5)$ & $84(54.5)$ & & & $F=3.395$ \\
\hline $8-10(n=71)$ & $41(57.7)$ & $30(42.3)$ & & & $\begin{array}{l}\mathrm{t}=0.890 \\
P=0.374\end{array}$ \\
\hline \multicolumn{6}{|c|}{ Screen time before lockdown(hrs) } \\
\hline $1-3(n=181)$ & $84(46.4)$ & $97(53.6)$ & $3.173(0.130)$ & $2.98(0.1280$ & $X^{2}=1.499, P=0.473$ \\
\hline $4-6(n=77)$ & $42(54.50)$ & $35(45.5)$ & & & $F=0.008$ \\
\hline $7-9(n=9)$ & $4(44.4)$ & $5(55.6)$ & & & $\begin{array}{l}\mathrm{t}=1.004 \\
P=0.316\end{array}$ \\
\hline \multicolumn{6}{|c|}{ Screen time during lockdown(hrs) } \\
\hline $1-<=3(n=21)$ & $10(47.6)$ & $11(52.4)$ & $6.28(0.233)$ & $6.44(0.227)$ & $X^{2}=1.284, P=0.733$ \\
\hline$>3-6(n=130)$ & $59(45.4)$ & $71(54.6)$ & & & $F=0.034$ \\
\hline $7-9(n=61)$ & $32(52.5)$ & $29(47.5)$ & & & $\mathrm{t}=1.191$ \\
\hline $10-14(n=55)$ & $29(52.7)$ & $26(47.3)$ & & & $P=0.235$ \\
\hline \multicolumn{6}{|c|}{ Time difference in screen time (hrs) } \\
\hline $\begin{array}{l}\text { No change/ reduced } \\
(\mathrm{n}=8)\end{array}$ & $4(50.0)$ & $4(50.0)$ & $3.65(0.198)$ & $3.45(0.176)$ & $\begin{array}{c}\mathrm{X}^{2}=1.197, P=0.754, \\
\mathrm{~F}=.0810,\end{array}$ \\
\hline $1-<=3(n=144)$ & $66(45.8)$ & $78(54.2)$ & & & $t=0.779$ \\
\hline$>3-6(n=89)$ & $46(51.7)$ & $43(48.3)$ & & & $P=0.437$ \\
\hline $7-9(26)$ & $14(53.8)$ & $12(46.2)$ & & & \\
\hline
\end{tabular}

\begin{tabular}{lccc}
\multicolumn{4}{l}{ Table 4: Effect of lockdown on the sleep wake } \\
pattern and daily time spent on electronic media
\end{tabular}

students complained of disturbance of night sleep very often during lockdown and half of respondents reported increase in daytime napping. Therefore, it can be said that, they managed their night time sleep deficit by daytime napping and delayed wake up time. The present survey did not find any significant age wise reduction in sleep duration. It must be noted that, the average sleep duration was not much hampered as an effect of lockdown, though it was marginally less than the recommended duration (>=7hrs)..$^{18}$ Two international surveys done by Blume et al., and Wright et al., from Europe and USA have pointed out increase amount of sleep duration as a consequence of decrease work pressure and social isolation. Sleep duration

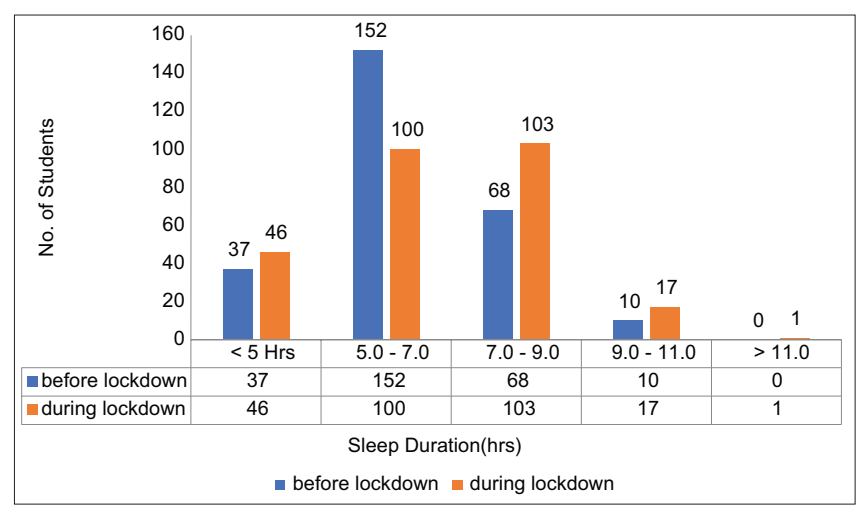

Figure 3: Daily sleep duration before lockdown vs. during lockdown

at night was increased by half an hour on weekdays and by 24 minutes on weekends. ${ }^{19,20}$ In a study from Argentina, it was seen that, both sleep onset and offset were delayed on weekdays only. The delay in the onset was less than the offset and the sleep schedule was more consistent. The lockdown effects were more on sleep among younger subjects. ${ }^{21}$ Females in the present study have more delayed onset for both sleep at night and wake up in morning during lockdown but not significant one. Similar result was reported from the study by Sinha M et al. ${ }^{10}$ The screen time spent by the females was marginally increased during lockdown in comparison to their male friends, whereas the sleep duration was less among female students irrespective of lockdown, 


\begin{tabular}{|c|c|c|c|}
\hline \multirow[t]{2}{*}{ Behavioral parameters } & \multicolumn{2}{|c|}{ Gender } & \multirow[t]{2}{*}{ Statistics } \\
\hline & $\begin{array}{c}\text { Male } \\
\text { Frequency (\%) }\end{array}$ & $\begin{array}{c}\text { Female } \\
\text { Frequency (\%) }\end{array}$ & \\
\hline \multicolumn{4}{|l|}{ Daytime napping } \\
\hline Increased $(n=145)$ & $72(49.7)$ & $73(50.3)$ & $X^{2}=1.737, P=0.633$ \\
\hline Decreased $(n=25)$ & $12(48.0)$ & $13(52.0)$ & \\
\hline No change $n=97$ ) & $53(54.6)$ & $44(45.4)$ & \\
\hline \multicolumn{4}{|l|}{ Disturbance in night sleep } \\
\hline Mostly $(n=40)$ & $20(50.0)$ & $20(50.0)$ & $X^{2}=7.899, P=0.048$ \\
\hline Often $(n=49)$ & $32(65.3)$ & $17(34.7)$ & \\
\hline Occasionally $(n=75)$ & $30(40.0)$ & $45(60.0)$ & \\
\hline No change $(n=103)$ & $55(53.4)$ & $48(46.6)$ & \\
\hline \multicolumn{4}{|l|}{ Physical activity } \\
\hline Decreased little $(n=64)$ & $42(65.6)$ & $22(34.4)$ & $X^{2}=9.941, P=0.019$ \\
\hline Decreased a lot $(n=123)$ & $57(46.3)$ & $66(53.7)$ & \\
\hline Increased $(n=52)$ & $21(40.4)$ & $31(54.6)$ & \\
\hline No change $(n=28)$ & $17(60.7)$ & $11(39.3)$ & \\
\hline \multicolumn{4}{|l|}{ Weight } \\
\hline Increased $(n=136)$ & $78(57.4)$ & $58(42.6)$ & $X^{2}=5.757, P=0.056$ \\
\hline Decreased $(n=41)$ & $15(36.6)$ & $26(63.4)$ & \\
\hline No change $(n=90)$ & $44(48.90$ & $46(51.1)$ & \\
\hline \multicolumn{4}{|l|}{ Mood status } \\
\hline Elevated $(n=44)$ & $28(63.6)$ & $16(36.4)$ & $X^{2}=3.361, P=0.186$ \\
\hline Low $(n=140)$ & $67(47.9)$ & $73(52.1)$ & \\
\hline No change $(n=83)$ & $42(50.6)$ & $41(49.4)$ & \\
\hline
\end{tabular}

not supported by earlier studies. ${ }^{10,22,23}$ In a six-week study carried in European countries, there was increase in sleep duration but the quality of sleep was slightly reduced during lockdown. There was also a decrease in mental and physical wellbeing. ${ }^{24}$ A study done in lockdown by Cellini et al. revealed increased usage of digital media at bedtime. However, sleep habits were not affected. The other reported changes in sleep-wake rhythms were delayed bedtime and wake up time, more time in bed, however sleep quality was lower. Similar reports were reflected in our study, too. ${ }^{25}$

\section{CONCLUSION}

Amidst the COVID-19 induced lockdown and shattered lifestyle of population, the current study has reflected significant effect of lockdown on some of the lifestyle attributes. Lockdown has resulted increased sleep duration and delayed bedtime and wake up time. This may lead to more stress and impaired state of mental well-being. Therefore, both personal and professional life may be affected soon. Our study has broadened the way for further research on sleep wake cycle and other lifestyle attributes during longer duration of social isolation.

\section{ACKNOWLEDGEMENT}

We sincerely express our gratitude to all the undergraduate medical students who have volunteered in the online survey.

\section{REFERENCES}

1. Huang C, Wang Y, Li X, Ren L, Zhao J, Hu Y, et al. Clinical features of patients infected with 2019 novel coronavirus in Wuhan, China. Lancet. 2020; 395: 497-506.

https://doi.org/10.1016/S0140-6736(20)30183-5

2. Zhou P, Yang X-L, Wang XG, Hu B, Zhang L, Zhang W, et al. A pneumonia outbreak associated with a new coronavirus of probable bat origin. Nature. 2020; 579: 270-273.

https://doi.org/10.1038/s41586-020-2012-7

3. World Health Organization. Global, India. [cited 2021 Jun 30] Available from:

https://covid19.who.int/region/searo/country/in

4. Ministry of Health and Family Welfare. Government of India. [cited 2021 Jun 30] Available from:

https://www.mohfw.gov.in

5. Andrews MA, Areekal B, Rajesh KR, Krishnan J, Suryakala R, Krishnan B, et al. First confirmed case of COVID-19 infection in India: A case report. Indian J Med Res. 2020; 151: 490-492. https://doi.org/10.4103/ijmr.IJMR_2131_20

6. Soni P. Effects of COVID-19 lockdown phases in India: an atmospheric perspective. Environ Dev Sustain. 2021; 1-12.

7. Roenneberg T, Kumar CJ and Merrow M. The human circadian clock entrains to sun time. Curr Biol. 2007; 17: 44-45. https://doi.org/10.1016/j.cub.2006.12.011

8. Wittmann M, Dinich J, Merrow M and Roenneberg T. Social jetlag: Misalignment of biological and social time. Chronobiol Int. 2006; 23: 497-509.

https://doi.org/10.1080/07420520500545979

9. Chandrashekaran MK, Marimuthu G, Subbaraj R, Kumaraswamy $P$, Ramkumar MS and Sripathi K. Direct correlation between the circadian sleep-wakefulness rhythm and time estimation in humans under social and temporal isolation. 
J Biosci. 1991; 16: 97-101. https://doi.org/10.1007/BF02703361

10. Sinha M, Pande B and Sinha R. Impact of COVID-19 lockdown on sleep-wake schedule and associated lifestyle related behavior: A national survey. J Public Health Res. 2020; 9:1826. https://doi.org/10.4081/jphr.2020.1826

11. Nag $C$ and Pradhan RK. Impact of television on sleep habits. Biol Rhythm Res. 2011; 43: 423-430. https://doi.org/10.1080/09291016.2011.599630

12. Nuutinen T, Ray $C$ and Roos E. Do computer use, TV viewing, and the presence of the media in the bedroom predict schoolaged children's sleep habits in a longitudinal study? BMC Public Health. 2013; 13: 684.

13. Yusuf $\mathrm{N}$ and Al-Banawi $\mathrm{N}$. The Impact of Changing Technology: The Case of E-Learning. Contemp Issues Educ Res. 2013; 6: 173-180.

https://doi.org/10.19030/cier.v6i2.7726

14. Eysenbach G. Improving the quality of Web surveys: The Checklist for Reporting Results of Internet E-Surveys (CHERRIES). J Med Internet Res. 2004; 6: 34. https://doi.org/10.2196/jmir.6.3.e34

15. MCTQ. The Questionnaire. [cited 2021 Jun 30] Available from: https://www.thewep.org/documentations/mctq

16. Natale V, Esposito MJ, Martoni $\mathrm{M}$ and Fabbri M. Validity of the reduced version of the morningness eveningness questionnaire. Sleep Biol Rhythms. 2006; 4: 72-76. https://doi.org/10.1111/j.1479-8425.2006.00192.x

17. Roenneberg T, Wirz-Justice A, Merrow M. Life between clocks: daily temporal patterns of human chronotypes. J Biol Rhythms. 2003; 18:80-90.

https://doi.org/10.1177/0748730402239679

18. Hirshkowitz M, Whiton K, Albert SM, Alessi C, Bruni O,
DonCarlos L, et al. National Sleep Foundation's sleep time duration recommendations: methodology and results summary. Sleep Health. 2015; 1: 40-43.

https://doi.org/10.1016/j.sleh.2014.12.010

19. Blume C, Schmidt MH and Cajochen C. Effects of the COVID-19 lockdown on human sleep and rest-activity rhythms. Curr Biol. 2020; 30: 795-797. https://doi.org/10.1016/j.cub.2020.06.021

20. Wright Jr KP, Linton SK, Withrow D, Casiraghi L, Lanza SM, de la Iglesia $\mathrm{H}$, et al. Sleep in university students prior to and during COVID-19 stay-at-home orders. Curr Biol. 2020; 30: 797 -798. https://doi.org/10.1016/j.cub.2020.06.022

21. Leone MJ, Sigman M and Golombek DA. Effects of lockdown on human sleep and chronotype during the COVID-19 pandemic. Curr Biol. 2020; 30:930-931. https://doi.org/10.1016/j.cub.2020.07.015

22. Cain SW, Dennison CF, Zeitzer JM, Guzik AM, Khalsa SBS, Santhi $\mathrm{N}$, et al. Sex differences in phase angle of entrainment and melatonin amplitude in humans. J Biol Rhythms. 2010; 25: 288-296. https://doi.org/10.1177/0748730410374943

23. Park $Y M$, Matsumoto $K$, Shinkoda $H$, Nagashima $H$, Kang MJ and Sheo YJ. Age and gender difference in habitual sleep-wake rhythm. Psychiatry Clin Neurosci. 2001; 55: 201-202. https://doi.org/10.1046/j.1440-1819.2001.00825.x

24. Blume C, Schmidt MH and Cajochen C. Effects of the COVID-19 lockdown on human sleep and rest-activity rhythms. Curr Biol. 2020; 30: 795-797. https://doi.org/10.1016/j.cub.2020.06.021

25. Cellini N, Canale N, Mioni G and Costa S. Changes in sleep pattern, sense of time and digital media use during COVID-19 lockdown in Italy. J Sleep Res. 2020; 29:13074. https://doi.org/10.1111/jsr.13074

\footnotetext{
Authors Contribution:

Authors Contribution: Revision of manuscript; IH- Review of literature, Editing and revision of manuscript, prepared first draft of manuscript; GB- Statistical analysis and interpretation, Review of literature, Manuscript preparation, editing and review; AG-Statistical analysis and interpretation

Work attributed to:

College of Medicine and JNM Hospital, West Bengal University of Health Science

Orcid ID:

Dr Sujata Biswas - (1) https://orcid.org/0000-0001-8661-7017

Dr Bhaskar Saha - (D) https://orcid.org/0000-0002-9274-3711

Mr. Indranil Halder - (1) https://orcid.org/0000-0002-5569-2265

Dr Gandhari Basu - (1) https://orcid.org/0000-0003-3394-1862

Mr. Anupam Ghosh - id https://orcid.org/0000-0001-9228-3893

Source of Support: Nil, Conflict of Interest: None declared.
} 